\title{
Congenital Lobar Emphysema in Early Adulthood
}

\author{
Sara Dâmaso ${ }^{1}$, Nuno R. Carreira ${ }^{1}$, Catarina Gonçalves ${ }^{1}$, Patrício Aguiar ${ }^{2}$ \\ 1. Serviço de Medicina 2, Hospital de Santa Maria, Centro Hospitalar Universitário Lisboa Norte, Lisboa, PRT 2. Serviço \\ de Medicina 1, Hospital de Santa Maria, Centro Hospitalar Universitário Lisboa Norte, Lisboa, PRT
}

Corresponding author: Nuno R. Carreira, nuno.reiscarreira@gmail.com

\begin{abstract}
Congenital lobar emphysema (CLE) is a rare developmental abnormality of the lower respiratory tract. This disease is caused by cartilage or connective tissue defects, leading to overdistention of a pulmonary lobe. CLE is mainly diagnosed in early childhood, though it might be rarely found in young adults. Due to its rarity, it can be misdiagnosed with other conditions. Here we report a case of a previously healthy young female complaining of dyspnea and thoracic pain after a commercial flight. Physical and radiological examinations were consistent with the diagnosis of CLE.
\end{abstract}

Categories: Emergency Medicine, Radiology, Pulmonology

Keywords: congenital lobar emphysema, congenital disease, hyperlucent lung, emergency radiology

\section{Introduction}

Congenital lobar emphysema (CLE), also known as congenital alveolar overdistension, congenital hyperlucent lobe or congenital lobar overinflation, is a developmental anomaly of the lower respiratory tract caused by defects in cartilage or connective tissue [1]. This condition affects males and females in a ratio of 3:1 and it has an estimated prevalence worldwide of about 1 in 20,000 to 1 in 30,000 live births [2,3]. CLE is characterized by the presence of a valve mechanism that causes airflow obstruction. The consequent air trapping leads to overdistention of one or more lobes [4]. The diagnosis is usually early in life, with $50 \%$ of patients diagnosed by four to six weeks of age. Less than $5 \%$ of patients are diagnosed after the age of six months [5]. However, cases of CLE diagnosed in early adulthood have been reported [5]. This paper reports a rare case of CLE that only became symptomatic in young adulthood.

\section{Case Presentation}

A 20-year-old German Caucasian female was admitted to the ED with complaints of dyspnea at rest and anterior thoracic pain. These symptoms started during a commercial flight, initially with enough severity to justify assistance in the airport after landing and emergent transportation to our hospital. She had no previous medical history except for an episode of bronchiolitis during childhood. No smoking, alcoholic or drug abuse habits were reported. On admission, the patient was already asymptomatic. Blood pressure, cardiac frequency and peripheral oxygen saturation were normal without supplemental therapy. On physical examination, a thoracic asymmetry was visible. Breath sounds were abolished in the left hemithorax and hyperresonance was noted at thoracic percussion. Laboratory evaluation including complete blood count, Creactive protein, $\mathrm{D}$-dimers, creatine kinase, lactate dehydrogenase, troponin and arterial blood gas test $(\mathrm{ABG})$ were unremarkable. Chest X-ray showed an hyperlucent left lung which was initially suspected to be 


\section{Cureus}

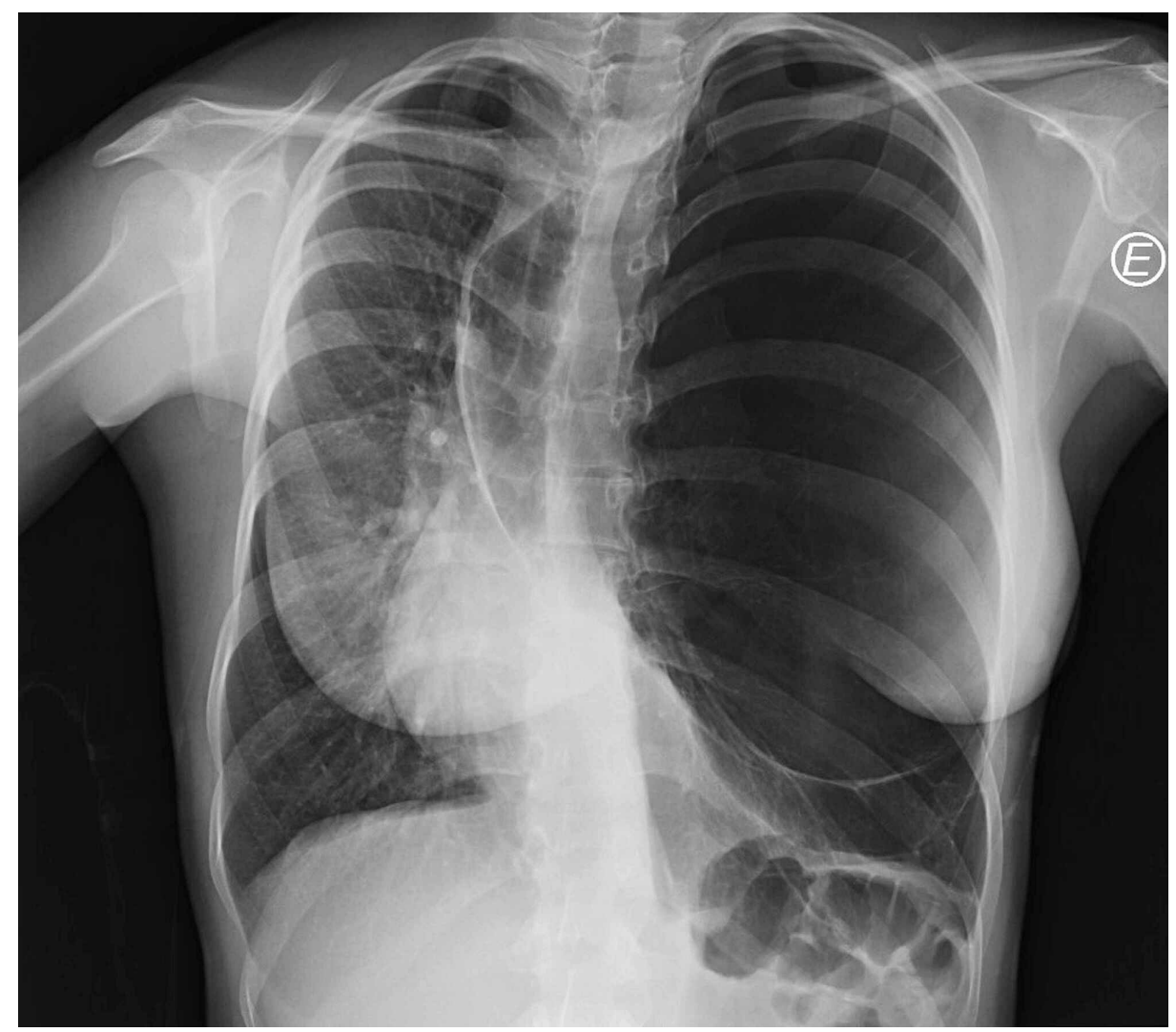

FIGURE 1: Chest radiograph.

Complete remission of symptoms, absence of hemodynamic instability, and ABG findings were, however, not suggestive of that hypothesis. A thoracic computed tomography (CT) was performed and described an area of hyperinflation occupying the upper two-thirds of the left lung $(23 \mathrm{~cm}$ in the longest axis) with scarce vasculature, causing contralateral mediastinal shift and compressive atelectasis of the remaining pulmonary parenchyma, suggestive of congenital lobar emphysema (Figures 2, 3).

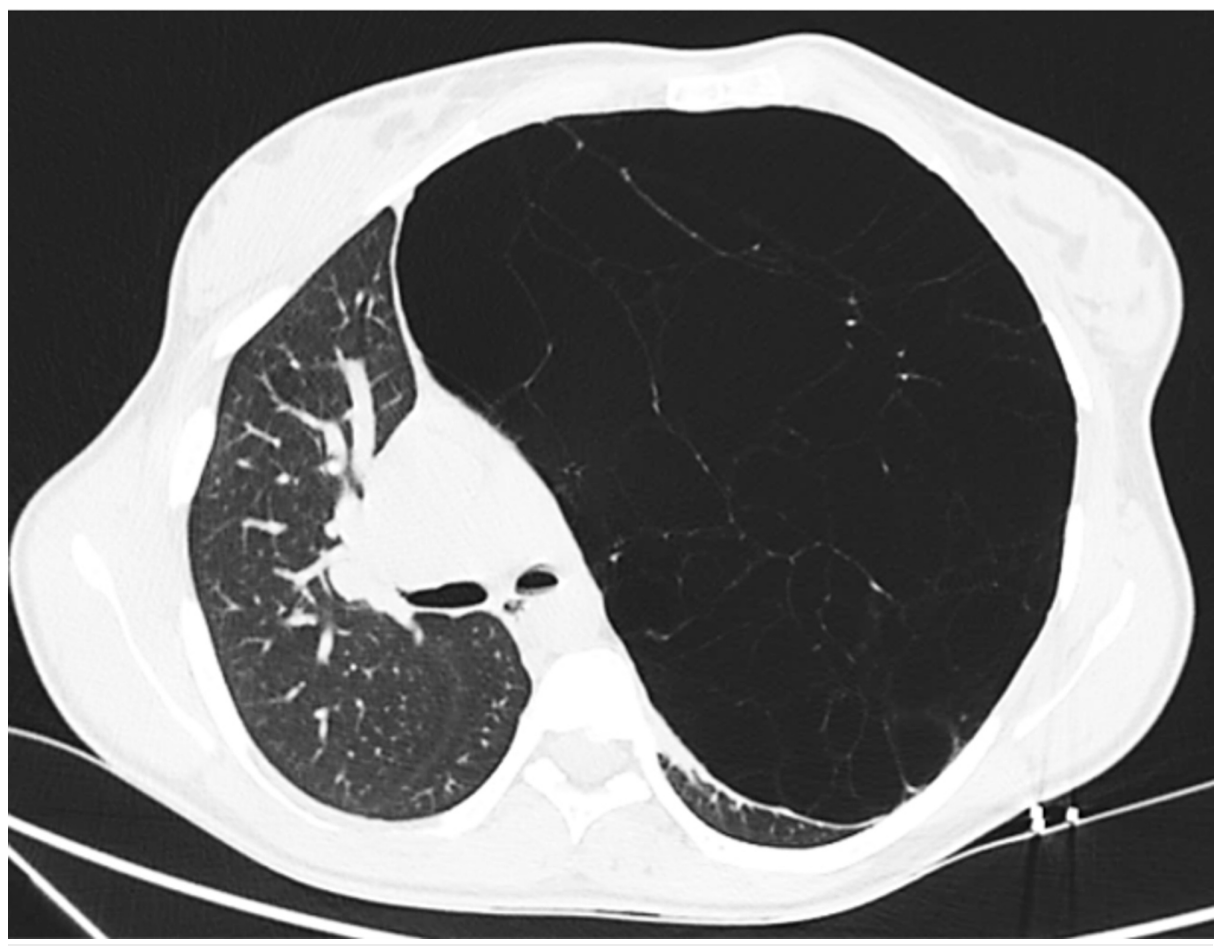

FIGURE 2: Chest computed tomography (axial). 


\section{Cureus}

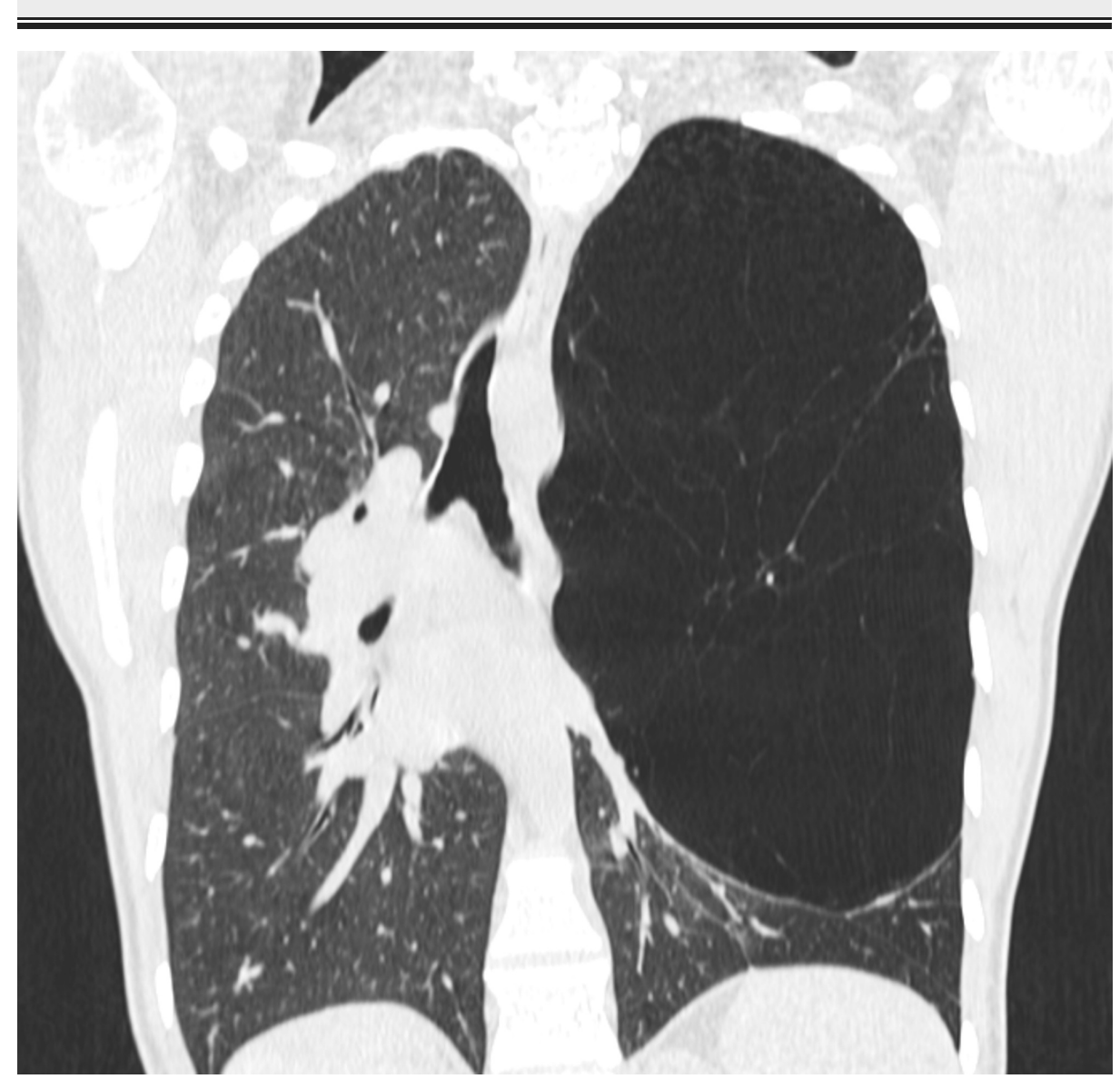

FIGURE 3: Chest computed tomography (coronal).

Based on clinical presentation and radiologic findings, a diagnosis of CLE was established and the patient was admitted to the medical ward for clinical surveillance. Afterwards, in the absence of symptoms that would justify immediate surgical management, a conservative approach was chosen.

\section{Discussion}

CLE is a congenital development defect of the lower respiratory tract characterized by overinflation of a pulmonary lobe. The most common forms arise in the left upper lobe (43\%) followed by the right middle lobe (32\%) [1]. An outflow obstruction causes the affected lobe to become overinflated with impaired ventilation/perfusion. Involvement of multiple lobes is highly uncommon [6]. Approximately $30 \%$ of cases are symptomatic at birth and the majority by the age of 12 months [7]. Rarely CLE is diagnosed in adult patients who did not experience any symptoms during childhood [6].

The etiology is unknown in about 50\% of CLE patients [1]. The most frequently identified cause of CLE is obstruction of the developing airway (25\% of cases). Other identified causes of CLE are summarized in Table 1. 


\section{Cureus}

Identified mechanisms of congenital lobar emphysema

\begin{tabular}{ll|} 
1. Bronchial disease & Bronchial stenosis \\
& Bronchial atresia \\
2. Vascular abnormalities & Bronchomalacia \\
& Pulmonary arterial sling anomalies \\
3. Extrinsic compression & Abnormal pulmonary venous return \\
& Bronchogenic cysts \\
& Mediastinal tumors
\end{tabular}

TABLE 1: Identified mechanisms of congenital lobar emphysema (adapted from Demir et al. 2019

[1]).

Signs and symptoms include tachypnea, wheezing, chronic cough and recurrent respiratory tract infections $[1,6]$. Physical examination reveals impaired thoracic expansion and use of accessory respiratory muscles, vocal fremitus and hyperresonance in the affected lobe area at thoracic percussion and diminished or abolished breath sounds at pulmonary auscultation [1]. Progressive overinflation over time can cause compression in the adjacent organs and displacement of mediastinal structures.

CLE is mainly a radiologic diagnosis. A posteroanterior chest X-ray should be the initial workup in patients with respiratory symptoms. Hyperlucency of the affected lobe can be seen accompanied by atelectasis of adjacent lobes and mediastinal shift to the opposite side [8]. Nonetheless, chest CT scan remains the gold standard for the diagnosis of CLE, as it allows evaluation of adjacent lobes and contralateral lung. Contrastenhanced CT is used to exclude vascular anomalies and mediastinal masses [9]. Removal of foreign bodies and search for anatomical variations might be done through bronchoscopy [10]. Ventilation-perfusion scan shows the characteristic decrease in ventilation and perfusion in the affected lobe [9]. Prenatal diagnosis can sometimes be made through ultrasonography; however, since CLE requires ventilation to be clinically evident, most cases are diagnosed after birth [11]. Echocardiographic evaluation is also necessary in these patients since CLE is accompanied by cardiac abnormalities in about $14 \%$ to $20 \%$ of cases [1].

The standard treatment for severe cases of CLE is lobectomy through thoracotomy [12]. In adults, the use of thoracoscopic approaches is increasing and may be considered. In cases mild symptomatic or asymptomatic where the patient is clinically stable, conservative treatment is a recommended option [1]. These patients should be followed closely due to potential clinical progression and future need for surgical intervention $[12,13]$.

\section{Conclusions}

The purpose of this report is to highlight a rare clinical entity with an uncommon late presentation. Only a few case reports of CLE in adults are described in the literature and differential diagnosis should be carefully assessed with most common lung diseases in adults. Its misdiagnosis may lead to unnecessary and even harmful procedures. In our case, the misinterpretation of the initial radiological findings with a hypertensive pneumothorax could lead to a needle thoracostomy approach. In this setting, this procedure might cause severe complications for the patient, for instance a permanent bronchopleural fistula. Finally, these patients must be managed according to radiological features and symptom severity.

\section{Additional Information \\ Disclosures}

Human subjects: Consent was obtained by all participants in this study. Conflicts of interest: In compliance with the ICMJE uniform disclosure form, all authors declare the following: Payment/services info: All authors have declared that no financial support was received from any organization for the submitted work. Financial relationships: All authors have declared that they have no financial relationships at present or within the previous three years with any organizations that might have an interest in the submitted work. Other relationships: All authors have declared that there are no other relationships or activities that could appear to have influenced the submitted work.

\section{References}

1. Demir OF, Hangul M, Kose M: Congenital lobar emphysema: diagnosis and treatment options. Int J Chronic 


\section{Cureus}

Obstruct Pulm Dis. 2019, 14:921-928. 10.2147/COPD.S170581

2. Thakral CL, Maji DC, Sajwani MJ: Congenital lobar emphysema: experience with 21 cases . Pediatr Surg Int. 2001, 17:88-91.10.1007/s003830000506

3. Kravitz RM: Congenital malformations of the lung. Pediatr Clin North Am. 1994, 41:453-472.

10.1016/s0031-3955(16)38765-X

4. Riedlinger WFJ, Vargas SO, Jennings RW, et al.: Bronchial atresia is common to extralobar sequestration, intralobar sequestration, congenital cystic adenomatoid malformation, and lobar emphysema. Pediatr Dev Pathol. 2006, 9:361-373. 10.2350/06-01-0023.1

5. Sadaqat M, Malik JA, Karim R: Congenital lobar emphysema in an adult . Lung India. 2011, 28:67-69. 10.4103/0970-2113.76307

6. Khalid M, Saleemi S, Khan B: Congenital lobar emphysema in adult: a rare case report . Respir Med CME. 2010, 150-152. 10.1016/j.rmedc.2009.09.010

7. Torregrosa CH, Medinilla EM, Ruiz EP, et al.: Congenital lobar hyperinflation: Conservative management as an alternative therapy. Ann Pediatr. 2014, 81:45-48. 10.1016/j.anpedi.2013.07.001

8. Bush A, Harcout J, Hewitt RJ, Nicholson AG: Congenital lung disease. Kendig's Disorders of the Respiratory Tract in Children. Wilmott RW, Deterding R, Li A, et al. (ed): Elsevier, Inc, Philadelphia, PA; 2019. 321-322.

9. Markowitz RI, Mercurio MR, Vahjen GA, et al.: Congenital lobar emphysema. The roles of CT and V/Q scan . Clin Pediatr. 1989, 28:19-23. 10.1177/000992288902800104

10. Karnak I, Senocak ME, Ciftci AO, et al.: Congenital lobar emphysema: diagnostic and therapeutic considerations. J Pediatr Surg. 1999, 34:1347-1351. 10.1016/s0022-3468(99)90009-X

11. Babu R, Kyle P, Spicer RD: Prenatal sonographic features of congenital lobar emphysema . Fetal Diagn Ther. 2001, 16:200-202. 10.1159/000053909

12. Ulku R, Onat S, Ozçelik C: Congenital lobar emphysema: differential diagnosis and therapeutic approach. Pediatr Int. 2008, 50:658-661. 10.1111/j.1442-200X.2008.02630.X

13. McDonald CF, Pierce RJ, Barter CE, et al.: Congenital lobar emphysema requiring surgery in adult life . Aust NZ J Med. 1986, 16:501-505. 10.1111/j.1445-5994.1986.tb02021.x 